\title{
Cognitive Profile of a Baby Girl Suffering From Agenesis of the Corpus Callosum (AgCC)
}

\author{
*Dweep Chand Singh and Jasmine Arora \\ Amity University, India
}

Submission: July 03, 2017; Published: July 05, 2017

*Corresponding author: Dweep Chand Singh, Associate Professor, AIBHAS, Amity University, A-7/1, II Floor, Matawali Gali, Via Rosary School Road, Uttar Pradesh, India, Tel: 09891424656 / 57; Email Id: drdweepsingh@gmail.com

\begin{abstract}
Background: Agenesis of the corpus callosum $(\mathrm{AgCC})$ encompasses a broad range of diagnoses. A synthesis of recent neonatal and prenatal imaging studies suggests that AgCC occurs in at least 1:4000 live births and. 3-5\% of individuals assessed for neuro developmental disorders had AgCC. Complete and partial AgCC, probably, result from disruption of the early stages of callosal development which could have genetic, infectious, vascular or toxic causes. All the patients show poor cognitive function and social interaction.

Aim: To present cognitive profile of a patient with AgCC.

Case: Five years old baby girl attended the Child Development Centre of a Government Hospital in New Delhi with the chief complaints of delayed development and poor social skills.

Tools: Developmental Profile II Alpern [1], Childhood Autism Rating Scale (CARS) Schopler [2], and Vineland Adaptive Behaviour Scale (VABS) Sparrow [3].

Results and discussion: $\mathrm{DA}=2$ years 5 months, $\mathrm{DQ}=46$; $\mathrm{CARS}$ score $=32$. A child with autism is characterized by poor social interactions. At times, it may be difficult to differentiate AgCC from autism. Therefore, a very careful history, mental status examination, radio imaging and psychological evaluation are warranted. Indeed, developmental profile of such children remains below normal. Biological functions are often supported by multiple structures - single physical feature is coded for by multiple genes, for example, so that knocking out any single gene can't prevent that feature from developing apparently normally. The ability of multiple different structures to support a single function is 'degeneracy'. It is a "ubiquitous biological property, a feature of complexity" and an inevitable outcome of natural selection. It explains both why unusual brain conditions are not as catastrophic as they might be, and also why scientists find the brain so confounding to try and understand.
\end{abstract}

Keywords: Corpus callosum; Agenesis

Abbreviations: AgCC: Agenesis of Corpus Callosum; CARS: Childhood Autism Rating Scale; VABS: Vineland Adaptive Behaviour Scale; DA: Developmental Age

\section{Introduction}

Background: Agenesis of the corpus callosum (AgCC) encompasses a broad range of diagnoses. A synthesis of recent neonatal and prenatal imaging studies suggests that AgCC occurs in at least 1:4000 live births Guillem [4]; Wang [5]. Other imaging studies Bodensteiner [6]; Jeret [7] demonstrated that 3-5\% of individuals assessed for neurodevelopment disorders had AgCC. Complete and partial AgCC, probably, result from disruption of the early stages of callosal development which could have genetic, infectious, vascular or toxic causes. Further heterogeneity in AgCC can arise from concomitant abnormalities in the anterior commissural. Agenesis of the corpus callosum (AgCC) may of two types: a) Complete AgCC: A congenital condition characterized by total absence of the corpus callosum, and

b) Primary AgCC: Primary AgCC refers to a symptom profile which includes isolated AgCC and generally intact intellectual functioning, as indicated by full-scale IQ $\geq 80$.

Cognitive profile of patients with AgCC: The most comprehensively examined higher cognitive domain in patients with AgCC is language. Individuals with primary AgCC have intact general naming, for example, naming objects from line drawings Liederman [8]; Temple [9] and receptive language, for example, comprehension of sentences and lexical reading 
skills Temple [10]. However, impairments have been reported in the comprehension of syntax and linguistic pragmatics, and in phonological processing and rhyming. With respect to linguistic pragmatics, persons with primary AgCC are impaired in the comprehension of idioms, proverbs, vocal prosody Brown [11] and narrative humour Brown [11] Within humour, they exhibit difficulty in overriding literal interpretation bias and are poor at using context to infer meaning. Patients with primary AgCC also show marked difficulties with expressive language, for example, in the verbal expression of emotional experience.

AgCC and neuropsychiatric disorders: The deficits in social communication and social interaction in patients with primary AgCC overlap with the diagnostic criteria for autism. Furthermore, people with primary AgCC may display a variety of other social, attention and behavioural symptoms that can resemble those of certain psychiatric disorders Happe [12]. Corpus callosum size, especially its anterior sectors, is also decreased in some cases of autism. Moreover, in one study, 8.5\% of individuals with AgCC had a diagnosis of autism, compared to only $1 \%$ of their siblings Doherty [13].

\section{The Present Case Having Agenesis of the Corpus Callosum (AgCC)}

Aim: To present cognitive profile of a patient with AgCC.

Case: Five years old baby girl $\mathrm{T}$ was brought to the Child Development Centre of a Government Hospital in New Delhi with the chief complaints of delayed development and poor social skills. The child was born to non-consanguineous parents. Pregnancy was full term and delivery was normal. Birth cry of the child was delayed and the birth weight was $1.5 \mathrm{~kg}$. In the prenatal history, the informant (mother) mentioned that she had abdominal pain after the first trimester of her pregnancy for which she had been on prescribed medications. Two days after birth, the child had jaundice for which she was treated successfully. The MRI report suggested complete agenesis of corpus callosum (AgCC).

Tools: Following tools were used for psychological assessment and the results are given hereunder:

Developmental Profile II Alpern [1]: Developmental Age $(\mathrm{DA})=2$ years 5 months andDevelopmental Quotient (DQ) $=46$ indicated moderate delay in developmental functioning.

Vineland Adaptive Behaviour Scale (VABS) Sparrow [3]: T's adaptive behaviour composite standard score of 61 summarized her overall level of adaptive functioning. The $95 \%$ confidence level showed that the chances were very good that T's true adaptive behaviour composite was within the low range. Her adaptive behaviour composite classified her general adaptive functioning as low.

Performance in Adaptive Behaviour Domain: Her standard scores in the adaptive behaviour domains along with the bands of error at the $95 \%$ level of confidence was as follows: communication $=59$, daily living skills $=53$, socialization $=81$. Her scores in the communication domains corresponded to a percentile rank of 0.3 which was at the low level; percentile rank of daily living skill was 0.1 showing low level, percentile rank for socialization was10 indicating moderately low level when compared with other children of the same age.

Performance in Sub-Domains: Child's v-scale cores in the sub-domains along with the bands of error at the 95 percent level of confidence were as follows: communication - receptive $=9$, expressive $=8$, written $=8$, daily living skills - personal $=$ 8 , domestic $=9$, community $=6$, socialization - interpersonal relationships $=13$, play and leisure time $=9$, and coping skills $=$ 13. Maladaptive Behaviours: V-scale scores in the maladaptive behaviour domain for sub domains internalizing, externalizing and overall maladaptive behaviour index were 5 and 13 respectively. All fell within the elevated and clinically significant levels indicating difficulties in getting along with others and forming peer relationships.

Childhood Autism Rating Scale (CARS) Schopler [2]: Scores $=32$ indicated mild to moderate autistic features

\section{Discussion}

Corpus callosum is very important part of the brain as it facilitates exchange of information between two hemispheres of the brain. Its pathology certainly hampers the communication resulting in poor cognitive and emotional development in the patient child. Previous studies indicated problems in comprehension of syntax and linguistic pragmatic (idioms, proverbs and vocal prosody Brown [11]. These may be apparent in verbal expression of emotional response. The present case performed poorly on the VABS, highlighting importance of corpus callosum in the adaptive behaviours in social transactions. Performance of child on CARS endorsed these findings as the scores indicated mild to moderate autistic features in the child. A child with autism is characterised by poor social interactions. At times, it may be difficult to differentiate AgCC from autism. Therefore, a very careful history, mental status examination, radio imaging and psychological evaluation are warranted. Indeed, developmental profile of such children remains below normal.

There are several reported cases that had missing or underdeveloped one or other part of the brain by their birth (not damaged after birth) Pattani [14]. For illustration, a woman had her cerebellum missing but a distinct structure found at the back of her brain. This was not just brain damage - the whole structure was absent. Yet the woman lived a normal life; she graduated from school, got married and had a kid following an uneventful pregnancy and birth. A pretty standard biography was of this 24-year-old woman. The woman wasn't completely unaffected she had suffered from uncertain, clumsy, movements her whole life. But the surprise is how she moved at all missing a part of the brain that is so fundamental it evolved with the first vertebrates. 
Brain scan of rare cases reveals the startling differences one can have inside the head. Part of the explanation for the brain's apparent resilience is its 'plasticity' - an ability to adapt its structure based on experience. Another clue comes from a concept advocated by Edelman $[15,16]$. He reports that biological functions are often supported by multiple structures - single physical feature is coded for by multiple genes, for example, so that knocking out any single gene can't prevent that feature from developing apparently normally. He called the ability of multiple different structures to support a single function 'degeneracy'. It is a «ubiquitous biological property, a feature of complexity" and an inevitable outcome of natural selection. It explains both why unusual brain conditions are not as catastrophic as they might be, and also why scientists find the brain so confounding to try and understand.

\section{References}

1. Alpern GD, Boll TJ, Shearer M (2000) Developmental Profile II. Western Psychological Services.

2. Schopler E, Reichler RJ, De Vellis RF (1980) "Toward objective classification of childhood autism: Childhood Autism Rating Scale (CARS)". J Autism Dev Disord 10(1): 91-103.

3. Sparrow SS, Cicchetti DV, Balla DA (2005) Vineland-II Adaptive Behavior Scales: Survey Forms Manual. Circle Pines, AGS Publishing, USA.

4. Guillem P, Fabre B, Cans C, Robert-Gnansia E, Jouk PS (2003) Trends in elective terminations of pregnancy between 1989 and 2000 in a French county (the Isere). Prenat Diagn 23(11): 877-888.

5. Wang LW, Huang CC, Yeh TF (2004) Major brain lesions detected on sonographic screening of apparently normal term neonates. Neuroradiology 46(5): 368-373.

6. Bodensteiner J, Schaefer GB, Breeding L, Cowan L (1994) Hypoplasia of the corpus callosum: a study of 445 consecutive MRI scans. J Child Neurol 9(1): 47-49.

7. Jeret JS, Serur D, Wisniewski K, Fisch C (1985) Frequency of agenesis of the corpus callosum in the developmentally disabled population as determined by computerized tomography. Pediatr. Neurosci. 12(2): 101-103.

8. Liederman J, Merola J, MartinezS (1985) Interhemispheric collaboration in response to simultaneous bilateral input. Neuropsychologia 23(5): 673-683.

9. Temple CM, Jeeves MA, Vilarroya O (1989) Ten pen men: rhyming skills in two children with callosal agenesis. Brain Language, 37(4): 548-564.

10. Temple CM, Jeeves MA, Vilarroya O (1990) Reading in callosal agenesis. Brain and Language 39(2): 235-253.

11. Brown WS, Symington M, Van Lancker-Sidtis D, Dietrich, Paul LK (2005) Paralinguistic processing in children with callosal agenesis: emergence of neurolinguistic deficits. Brain Lang 93(2): 135-139.

12. Happe F (2006) Time to give up on a single explanation for autism. Nature Neurosci. 9(10): 1218-1220.

13. Doherty D, Tu S, Schilmoeller K, Schilmoeller G (2006) Health-related issues in individuals with agenesis of the corpus callosum. Child Care Health Dev 32(3): 333-342.

14. Pattani A (2016) Preliminary Research - Living without Brain Structures. Story Lab.

15. Edelman GM (1978) The Mindful Brain: Cortical Organization and the Group-selective Theory of Higher Brain Function. MIT Press, USA.

16. Stafford T (2014) Can you live a normal life with half a brain? Neurohacks.

\section{Your next submission with Juniper Publishers} will reach you the below assets

- Quality Editorial service

- Swift Peer Review

- Reprints availability

- E-prints Service

- Manuscript Podcast for convenient understanding

- Global attainment for your research

- Manuscript accessibility in different formats

( Pdf, E-pub, Full Text, Audio)

- Unceasing customer service

Track the below URL for one-step submission

https://juniperpublishers.com/online-submission.php 